\title{
Evidence for Brainstem and Supra-Brainstem Contributions to Rapid Cortical Plasticity in Adult Monkeys
}

\author{
J. Xu and J. T. Wall \\ Department of Neurobiology and Anatomy, Medical College of Ohio, Toledo, Ohio 43699-0008
}

Cortical maps can undergo amazingly rapid changes after injury of the body. These changes involve functional alterations in normal substrates, but the cortical and/or subcortical location(s) of these alterations, and the relationships of alterations in different substrates, remain controversial. The present study used neurophysiological approaches in adult monkeys to evaluate how brainstem organization of tactile inputs in the cuneate nucleus $(\mathrm{CN})$ changes after acute injury of hand nerves. These data were then compared with analogous data from our earlier cortical area $3 \mathrm{~b}$ studies, which used the same approaches and acute injury, to assess relationships of cuneate and cortical changes. The results indicate that cuneate tactile responsiveness, receptive field locations, somatotopic organization, and spatial properties of representations (i.e., location, continuity, size) change during the first minutes to hours after injury. The comparisons of cuneate and area $3 b$ organization further show that some cuneate changes are preserved in area $3 b$, whereas other cuneate changes are transformed before being expressed in area $3 \mathrm{~b}$. The findings provide evidence that rapid reorganization in area $3 b$, in part, reflects mechanisms that operate from a distance in the cuneate nucleus and, in part, reflects supracuneate mechanisms that modify brainstem changes.

Key words: neuronal plasticity; somatosensory cortex; dorsal column nuclei; lemniscal mechanisms; disinhibition; sensitization; tactile processing; primate cuneate nucleus
Cortical and subcortical substrates of the CNS contain organized maps of tactile inputs from the skin. Long-standing peripheral injury in adult primates causes map reorganization in cortical area $3 \mathrm{~b}$ that, in part, reflects subcortical and cortical anatomical changes that slowly develop over months to years (Florence et al., 1998; Jones and Pons, 1998). These slow changes are preceded by functional changes in normal anatomical substrates, the first of which can be expressed with surprising quickness; for example, initial functional alterations of tactile inputs in area $3 \mathrm{~b}$ begin within minutes to hours after various hand injuries (Merzenich et al., 1983; Calford and Tweedale, 1991; Kolarik et al., 1994; Silva et al., 1996). In contrast to long-standing changes, there is little understanding of whether or how subcortical alterations contribute to these rapid cortical changes (for review, see Florence et al., 1997). The contributions of brainstem substrates remain especially unclear because studies of the cuneate, gracile, and trigeminal nuclei present a controversial mix of positive (Dostrovsky et al., 1976; Millar et al., 1976; Pettit and Schwark, 1993, 1996; Panetsos et al., 1995; Faggin et al., 1997) and negative (McMahon and Wall, 1983; Waite, 1984; Northgrave and Rasmusson, 1996; Zhang and Rowe, 1997) evidence for acute reorganization in the brainstem.

A recent study indicates that functional changes appear in the main cuneate nucleus ( $\mathrm{CN})$ of adult monkeys within minutes after hand injury (Xu and Wall, 1997a). This finding prompted the present experiments to further study $\mathrm{CN}$ changes during this initial postinjury period and to evaluate whether initial $\mathrm{CN}$ and cortical changes are related. To examine these issues, neurophys-

Received March 29, 1999; revised May 18, 1999; accepted June 15, 1999.

This work was supported by National Institutes of Health Grant NS21105. We thank Marshonna Forgues and Jessica Nguyen for their technical assistance, and Richard Lane and Andrey Stojic for helpful discussions.

Correspondence should be addressed to J. T. Wall, Department of Neurobiology and Anatomy, Medical College of Ohio, P.O. Box 10008, Toledo, OH 43699-0008. Copyright (C) 1999 Society for Neuroscience $0270-6474 / 99 / 197578-13 \$ 05.00 / 0$ iological approaches were used to evaluate how tactile inputs from the hand and adjacent body are organized in the $\mathrm{CN}$ of adult squirrel monkeys after acute section of nerves (median and ulnar) to the hand. These data were then compared with corresponding area $3 \mathrm{~b}$ data from our previous studies of adult squirrel monkeys that had the same acute injury and that were assessed using identical approaches (Kolarik et al., 1994). The following questions were addressed: how are features of tactile input organization in the $\mathrm{CN}$ of adult primates changed in the first minutes to hours after injury, and how are functional changes in $\mathrm{CN}$ and area $3 \mathrm{~b}$ hand maps related during this period?

\section{MATERIALS AND METHODS}

All protocols followed the guidelines of the National Institutes of Health Guide for the Care and Use of Laboratory Animals and were approved by the Institutional Animal Care and Use Committee at the Medical College of Ohio.

Samples and animal preparation. All data are from adult squirrel monkeys. Postinjury $\mathrm{CN}$ data were derived from five monkeys that had ipsilateral acute sections of the median and ulnar nerves. Data from these monkeys were compared with preinjury data from these monkeys and with $\mathrm{CN}$ data from an additional 10 monkeys that had normal nerves (Xu and Wall, 1999). In CN studies, systematic grids of recording sites were made around rostrocaudal levels where the nucleus and its pars rotunda subdivision are largest. These levels contain the main part of the $\mathrm{CN}$ hand representation (Florence et al., 1991; Xu and Wall, 1996, 1999) and thus the main ascending lemniscal substrates for hand inputs. Area $3 \mathrm{~b}$ data were derived from 12 monkeys, 5 that had contralateral acute sections of the median and ulnar nerves (Kolarik et al., 1994) and 7 that had normal nerves (Wall et al., 1993; our unpublished observations).

Except for differences in surgeries to expose the medulla versus cortex, all monkeys were prepared with comparable procedures that have been described previously (Wall et al., 1993; Kolarik et al., 1994; Xu and Wall, 1996, 1997a, 1999). Briefly, for initial surgical and subsequent recording procedures, monkeys were maintained at a surgical plane of anesthesia with a mixture of ketamine hydrochloride $(25-50 \mathrm{mg} / \mathrm{kg}$, i.m.) and acepromazine $(0.4-0.8 \mathrm{mg} / \mathrm{kg}, \mathrm{i} . \mathrm{m}$.). After the head was secured in a frame, the dorsal medulla or parietal cortex was exposed, covered with silicone fluid, and photographed $(30-40 \times)$. 


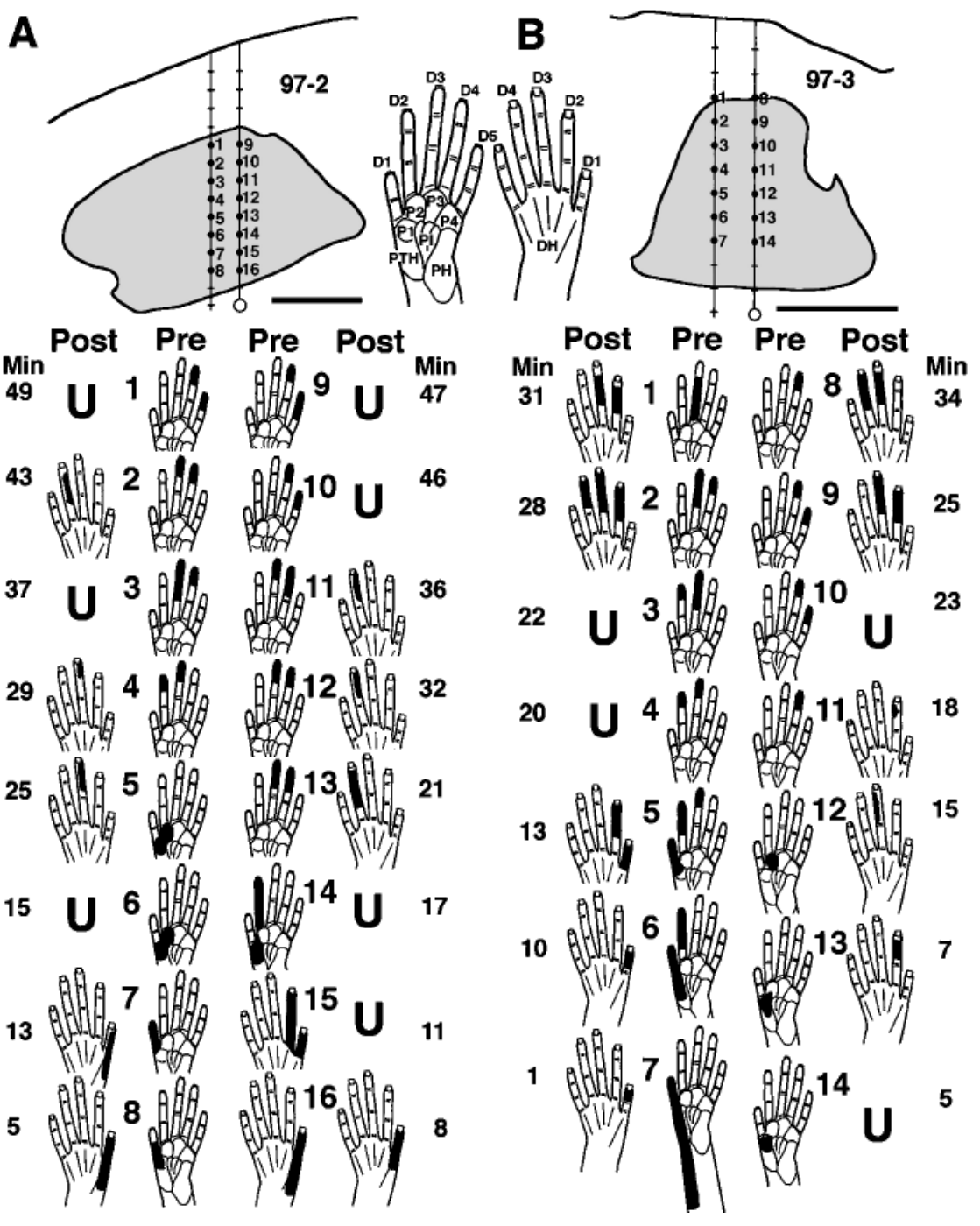

Figure 1. Shifts in tactile receptive field locations and responsiveness during the first minutes after nerve section. Top, Transverse plane camera lucida drawings of reconstructed tracks in the $\mathrm{CN}$ (shaded) of two monkeys $(A, B)$. Hand pictures of the glabrous (left $)$ and dorsal (right) sides of the hand indicate abbreviations for digits (D1-D5), palmar pads $(P)$, and the dorsal hand area opposite the palm $(D H)$. Bottom, The indicated preinjury receptive fields (Pre) were recorded as two coupled electrodes were advanced stepwise from dorsal (i.e., sites $1+9$ in $A$ and $1+8$ in $B$ ) to ventral (i.e., immediately below sites $8+16$ in $A$ and $7+14$ in $B$ ) locations in the preinjury glabrous hand representation. Nerve section was then performed (each nerve was previously looped with suture to permit simultaneous sectioning), and postinjury responses (Post) were assessed as the electrodes were immediately retracted stepwise up the same tracks over the subsequent 34-49 min (Min). Note (1) preinjury tactile receptive fields that were restricted to glabrous skin shifted to dorsal hand skin within minutes, (2) shifts frequently involved changes from the glabrous to dorsal side of the same and/or adjacent digit(s), and (3) some sites became unresponsive to tactile stimuli $(U)$. Scale bar, $500 \mu \mathrm{m}$.
Nerve injury. Transection of the median and ulnar nerves was performed as described previously (Kolarik et al., 1994). One or two incisions were made along the wrist, the median and ulnar nerves were localized and freed from surrounding tissue, and a loop of suture was passed beneath each nerve. Incisions were closed except for openings for each loop. Both nerves were subsequently rapidly and simultaneously transected by elevating the loops and cutting the nerves with scissors. From previous nerve recordings (Wall et al., 1993), and from the locations of residual fields after injury (see Results), this injury denervated all glabrous skin and parts of the dorsal (hairy) surface on the little finger and adjacent edge of the hand. Radial nerve innervation to the other parts of the dorsal hand remained intact.

Neurophysiological recording, stimulation, and receptive field definition. Tungsten or stainless steel microelectrodes (1-4 M $\Omega$ ) were inserted perpendicular to the dorsal surface of the medulla or area $3 \mathrm{~b}$, and the entry points were marked on the photograph. For $\mathrm{CN}$ recording, up to four electrodes that were coupled in a row with tips aligned and 100-200 $\mu \mathrm{m}$ apart were used to sample mediolateral rows of recording sites. Use of coupled electrodes simplified reconstructions of tracks because distances between electrodes were fixed and measurable. Receptive fields were defined from multiunit and occasionally single unit activity encountered at successive dorsal-to-ventral recording sites. When responses indicated that electrodes had advanced below the $\mathrm{CN}$, marking lesions were made at selected sites (3-8 $\mu \mathrm{A}, 2-4 \mathrm{sec})$. These procedures were reiterated with the aim of producing a transverse plane grid that sampled responses at intervals of $\sim 50-100 \mu \mathrm{m}$ in the dorsoventral and 100-200 $\mu \mathrm{m}$ in the mediolateral dimensions. The multiunit methods were capable of detecting changes in tactile responsiveness (e.g., responsive vs nonresponsive) and extents or locations of receptive fields with recording site shifts of $50-70 \mu \mathrm{m}$, indicating that neurons were sampled over a diameter of $100-140 \mu \mathrm{m}$ (or area of $0.008-0.015 \mathrm{~mm}^{2}$ ).

The procedures for area $3 \mathrm{~b}$ recording have been described (Wall et al., 1993; Kolarik et al., 1994). Area 3b hand maps in four monkeys with acutely sectioned nerves and three monkeys with normal nerves were studied in detail (Wall et al., 1993; Kolarik et al., 1994). In these cases, recording sites were uniformly spaced $\sim 200-300 \mu \mathrm{m}$ apart across the entire area $3 b$ hand representation. In one additional monkey with acute injury and four monkeys with normal nerves, delimited parts of the area $3 \mathrm{~b}$ hand map were studied in detail. In all area $3 \mathrm{~b}$ studies, receptive fields were defined from multiunit, or occasionally single unit, activity encountered around the middle layers, 400-900 $\mu \mathrm{m}$ below the surface. After recording, selected sites were marked to permit reconstruction of recording sites with respect to the histological borders of area $3 \mathrm{~b}$.

Equivalent stimulation procedures and criteria for defining tactile receptive fields were used in the $\mathrm{CN}$ and area $3 \mathrm{~b}$. As described previously (Wall et al., 1993; Kolarik et al., 1994; Xu and Wall, 1996, 1999), stimuli were hand-delivered punctate contacts or brushes of the skin, hairs, or deep tissues. To define cutaneous receptive fields, light tactile stimuli were presented to activate low-threshold cutaneous inputs directly beneath the probe. A cutaneous receptive field was defined as the area of skin from which responses were elicited to light cutaneous stimulation; i.e., both preinjury and postinjury fields reflected the total skin area that evoked action potentials. Each field was judged to reflect a maximal, low-threshold cutaneous field area. These maximal fields are somewhat larger than minimal cutaneous fields as defined in other studies in squirrel monkeys (Sur et al., 1982; Merzenich et al., 1987).

The procedures for delineating and measuring tactile receptive fields on the hand have been described (Xu and Wall, 1999). Fields were drawn 
Figure 2. Postinjury recording sites and related receptive fields for a representative $\mathrm{CN}$ transverse plane map. Top left, Transverse plane camera lucida drawing of the CN (shaded). Vertical lines indicate 15 electrode penetrations, small black dots indicate $\mathrm{CN}$ recording sites, hash marks indicate sites outside the $\mathrm{CN}$, and larger black and white circles indicate marker lesions $($ dorsal $=u p ;$ medial $=$ right $)$. Scale bar, $1 \mathrm{~mm}$. Bottom, Tactile receptive fields (black areas) for $\mathrm{CN}$ sites with corresponding number. Numbered sites for which no field is shown were not responsive to tactile stimulation. Note that neurons with tactile fields involving the hand were in central $\mathrm{CN}$ locations (e.g., tracks below sites 14, 26, 38, and 50), and all hand fields were on the dorsal (hairy) hand.
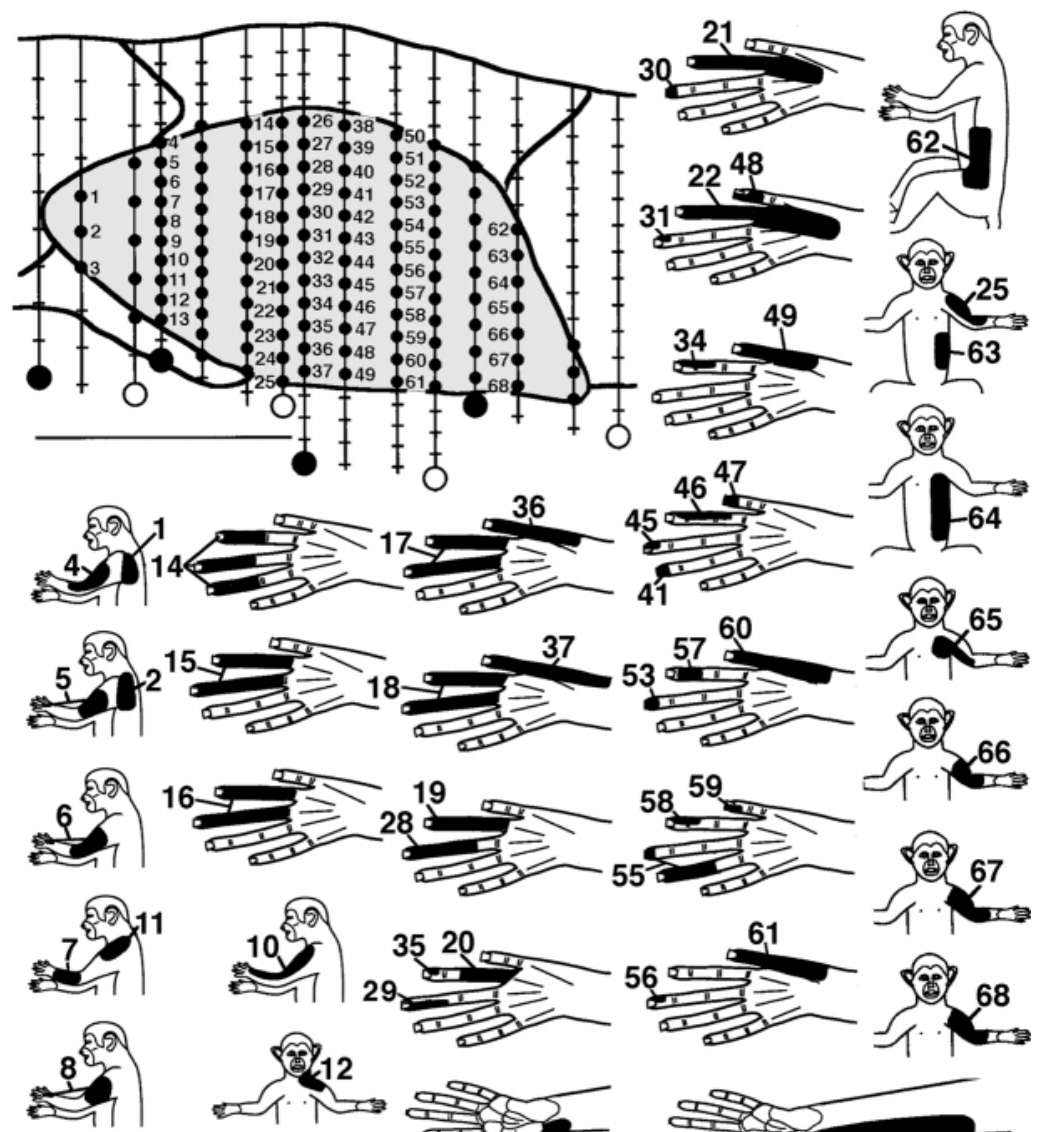

61
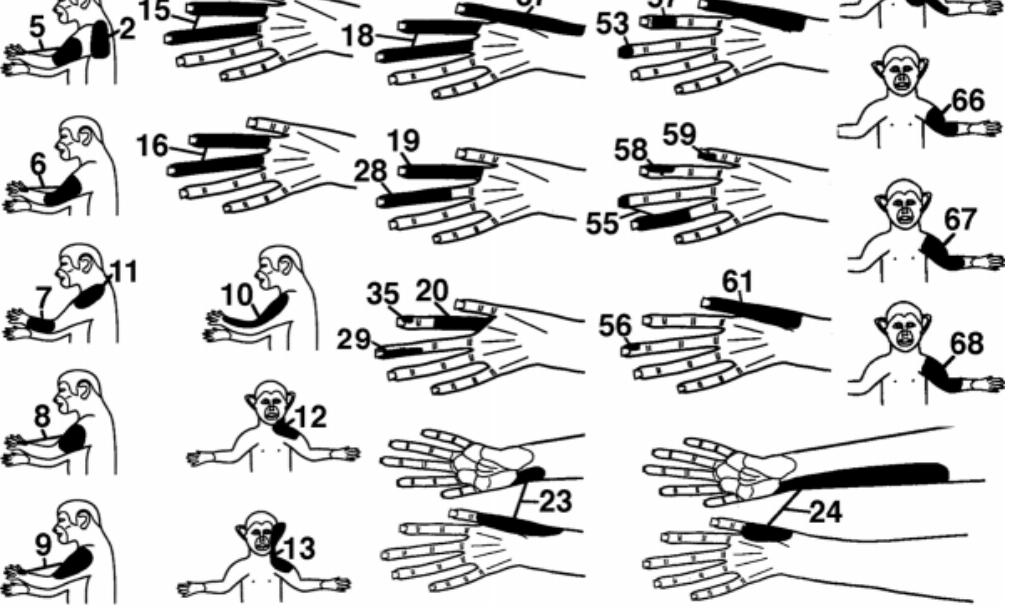

on diagrams that illustrated the borders of each hand part and measured with a computerized planimeter. $\mathrm{CN}$ and area $3 \mathrm{~b}$ fields were normalized in the same way to percentages of the total hand surface. These procedures permitted comparisons of the relative sizes of $\mathrm{CN}$ and area $3 \mathrm{~b}$ fields without confounds attributable to differences in absolute hand size. Receptive field data were mainly derived from multiunit responses; however, single unit fields were also encountered and were similar to multiunit fields.

Histological reconstructions and delineation and measurement of representations. These procedures have been described (Wall et al., 1993; Kolarik et al., 1994; Xu and Wall, 1996, 1999). In brief, after recording, monkeys were overdosed with barbiturate and perfused with saline and paraformaldehyde. In all $\mathrm{CN}$ experiments, the medulla was frozen and cut into $50-\mu \mathrm{m}$-thick transverse sections. All sections were co-processed with cytochrome oxidase $(\mathrm{CO})$ to identify $\mathrm{CN}$ borders and $\mathrm{CO}$ dense patches in the pars rotunda, and with the Prussian blue method to distinguish iron deposits made with stainless steel microelectrodes from electrolytic marks made with tungsten microelectrodes. Grids of $\mathrm{CN}$ recording sites were reconstructed using depth estimates from microdrive readings and camera lucida images of histologically observed track artifacts and fiducial marks. In all area $3 \mathrm{~b}$ experiments, the parietal cortex was frozen and cut into 50- $\mu \mathrm{m}$-thick parasagittal sections. All sections were stained with cresyl violet, and the architectonic borders of area $3 \mathrm{~b}$ were related to track artifacts and fiducial marks. All CN and area $3 \mathrm{~b}$ neuronal data were histologically confirmed to be in these structures.

$\mathrm{CN}$ and area $3 \mathrm{~b}$ responses were used to define representations of the hand and adjacent parts of the body (Wall et al., 1993; Kolarik et al., 1994; Xu and Wall, 1996, 1999). Briefly, each recording site was labeled according to its receptive field location. Borders delimiting groups of recording sites with fields on a targeted skin area(s) (e.g., digits, dorsal hand, forelimb) were placed either midway between sites with fields that did and did not include the targeted area(s) or, alternatively, on sites having fields that partly included the targeted area(s). The same border

criteria were applied in the $\mathrm{CN}$ and area $3 \mathrm{~b}$, thus providing a means of comparing spatial sizes, continuities, and adjacencies of representations of particular skin areas. Areas within borders of representations were measured with a computerized planimeter. Only fully mapped representations of the hand in area $3 \mathrm{~b}$ and in $\mathrm{CN}$ transverse planes were used for analyses of representations (postinjury: $\mathrm{CN}=11$ maps, area $3 \mathrm{~b}=4$ maps; normal: $\mathrm{CN}=14$ maps, area $3 \mathrm{~b}=3$ maps). For analyses in which extensive bracketing of representations was not necessary (e.g., analyses of receptive fields), data from maps that were incompletely defined were used to supplement data from full maps (postinjury: $\mathrm{CN}=6$ maps, area $3 \mathrm{~b}=1$ map; normal: $\mathrm{CN}=5$ maps, area $3 \mathrm{~b}=4$ maps).

Previous studies of $\mathrm{CN}$ organization in normal squirrel monkeys demonstrated that tactile inputs from all or most of the hand surface map onto a transverse plane through the pars rotunda and that similar organization is repeated in planes at different rostrocaudal levels (Florence et al., 1991; Xu and Wall, 1999). A similar concept applies to hand maps in tangential planes parallel to the layers of area $3 \mathrm{~b}$. Thus, two-dimensional hand maps through the respective transverse and tangential planes of the $\mathrm{CN}$ and area $3 \mathrm{~b}$ provide estimates of spatial properties of maps in these structures. The results define organization in these planes.

\section{RESULTS}

\section{CN postinjury organization}

Receptive fields and tactile responsiveness

Median and ulnar nerve section, which denervated the glabrous hand, triggered rapid shifts in locations of cutaneous receptive fields and losses of tactile responses. In experiments in which the same or similar neurons were recorded before and after injury, $\mathrm{CN}$ sites with preinjury tactile responses on the hand underwent receptive field shifts from the glabrous to dorsal hand, across the 

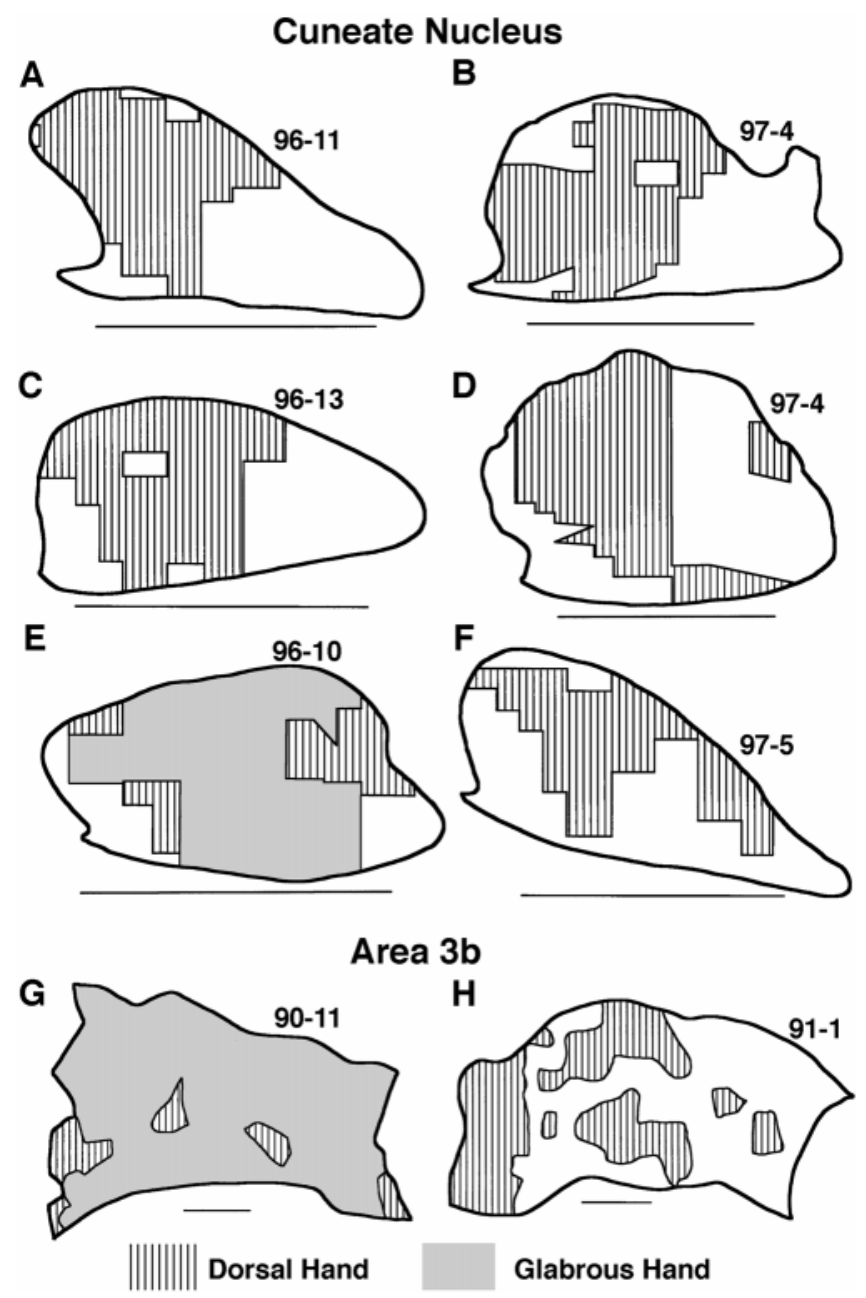

Figure 3. Consistently observed features of hand maps in the $\mathrm{CN}(A-F)$ and area $3 \mathrm{~b}(G, H)$. Note that (1) normally in both the $\mathrm{CN}(E)$ and area $3 \mathrm{~b}(G)$, the glabrous representation (gray) is continuous and large, whereas the dorsal representation (striped) occupies adjacent, discontinuous, small patches, and (2) after injury, the dorsal representation in the $\mathrm{CN}$ (striped) enlarged and became continuous across central CN locations normally representing glabrous inputs $(A-D$ and $F$ vs $E$ ), whereas the dorsal representation in area $3 \mathrm{~b}$ also enlarged into area $3 \mathrm{~b}$ locations normally representing glabrous inputs, but remained discontinuous and patchy (striped; $H$ vs $G$ ) (see Fig. 7 for further examples). For CN maps, dorsal $=u p$ and medial $=$ right. Scale bar, $1 \mathrm{~mm}$. For area $3 \mathrm{~b}$ maps, anterior $=u p$ and medial $=$ right. Scale bar, $1 \mathrm{~mm}$.

dorsal hand, or infrequently, from the hand to forelimb. Preinjury neuronal responses that were restricted to glabrous skin shifted to dorsal skin fields within minutes and remained apparent or continued to develop over the next several hours (Fig. 1). These shifts commonly involved changes from the glabrous to dorsal side of the same and/or adjacent digit(s), suggesting that preinjury and postinjury fields were in rough register (Fig. $1 A, 4,7,8,11 ; 1 B, 1$, $5,6,8)$. In contrast to neurons that had shifted fields, neurons at other $\mathrm{CN}$ sites lost tactile responsiveness after injury (Fig. 1) (see below).

The representation of the hand and sizes of receptive fields on the hand

In experiments in which $\mathrm{CN}$ planes were mapped in high detail after injury (Fig. 2), receptive field shifts to the dorsal hand were further reflected by increased incidences of dorsal hand fields and
Table 1. Mean (SD) sizes of representations as percentages of $\mathrm{CN}$ transverse areas in normal and postinjury animals

\begin{tabular}{llc} 
Cuneate & Normal & Postinjury \\
\hline Total hand & $53.1(9.3)$ & $35.1(14.4)$ \\
$\quad$ Glabrous & $38.5(8.0)$ & 0 \\
Hairy & $14.6(4.9)$ & $35.1(14.4)$ \\
Forelimb, trunk, face & $38.1(8.8)$ & $37.3(2.8)$ \\
Cutaneously unresponsive & $8.8(5.7)$ & $27.6(14.2)$ \\
\hline
\end{tabular}

by consistent changes in the location, continuity, size, and somatotopic organization of $\mathrm{CN}$ representations of the dorsal hand. In transverse planes of the $\mathrm{CN}$, the representation of the glabrous hand is normally a large, continuous representation occupying all or most of the pars rotunda, distinguished by its densely stained $\mathrm{CO}$ patches; in contrast, the representation of the dorsal hand is normally distributed in discontinuous small areas, mainly along the lateral, or lateral and medial, edges of the glabrous hand representation (Fig. 3E) (Xu and Wall, 1996, 1999). After injury, the $\mathrm{CN}$ dorsal hand representation consistently became more continuous and enlarged by approximately 2.4 times from a normal mean of $14.6 \%$ to a postinjury mean of $35.1 \%$ of the $\mathrm{CN}$ transverse plane $(t[11]=4.1 ; p<0.002)$ (Fig. 3, compare $E$, $A-D, F$; Table 1). These enlarged dorsal hand representations consistently spanned pars rotunda patches in central $\mathrm{CN}$ locations where the glabrous hand representation is normally located (Figs. 3,4).

The normal CN hand map occupies a mean area of $53.1 \%$ of $\mathrm{CN}$ transverse planes (Table 1). Thus, relative to this area, the dorsal hand representation expanded from a normal mean area equivalent to $27.4 \%$ (i.e., $14.6 / 53.1$ ) to a postinjury mean area equivalent to $66.1 \%$ (i.e., $35.1 / 53.1$ ) of the mean size of normal $\mathrm{CN}$ hand maps (Fig. 5). These findings, and the above changes in

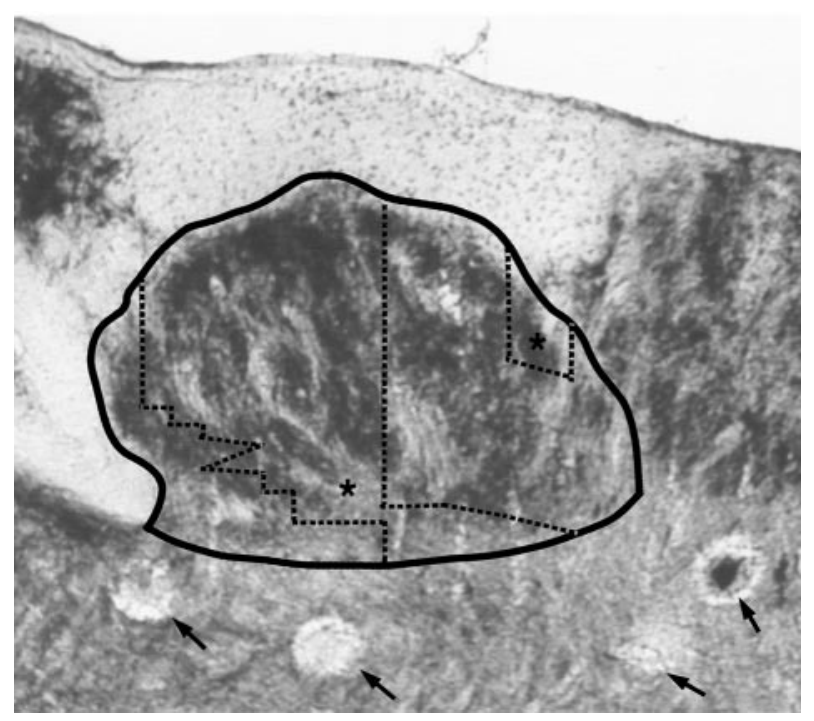

Figure 4. Cytochrome oxidase (CO) stained transverse section of the brainstem showing the $\mathrm{CN}$ (solid border) and the postinjury dorsal hand representation (areas indicated by * between dotted lines). The postinjury dorsal hand representation occupies pars rotunda locations containing $\mathrm{CO}$ dense patches that are normally associated with glabrous hand inputs (Xu and Wall, 1999). Arrows indicate marker lesions at the bottoms of some of the penetrations made in this transverse plane. Dorsal $=u p$; medial $=$ right . 


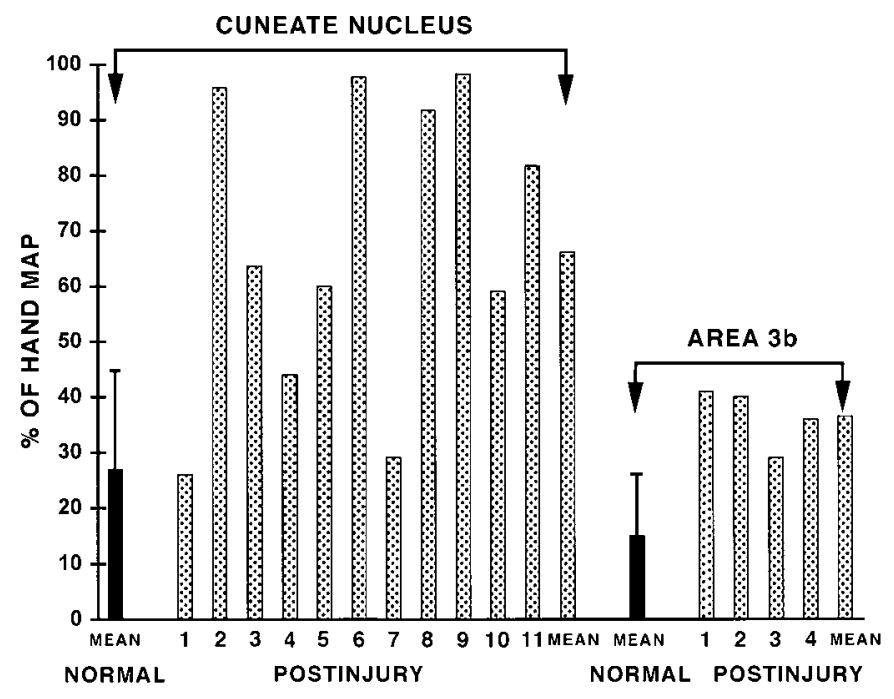

Figure 5. Normal and postinjury sizes of dorsal hand representations in the $\mathrm{CN}$ and area $3 \mathrm{~b}$. For $\mathrm{CN}$ measures (left), NORMAL MEAN indicates mean and $95 \%$ confidence interval sizes of normal $\mathrm{CN}$ dorsal hand representations [14 maps; Xu and Wall (1999)]; POSTINJURY 1-11 and $M E A N$ indicate postinjury sizes of dorsal hand representations for 11 maps and their mean. For area $3 \mathrm{~b}$ measures (right), NORMAL MEAN indicates mean and $95 \%$ confidence interval sizes of normal area $3 \mathrm{~b}$ dorsal hand representations [3 maps; Wall et al. (1993)]; POSTINJURY 1-4 and MEAN indicate postinjury sizes of dorsal hand representations for four maps and their mean. See Results for details.

location and continuity of the dorsal hand representation, suggest that approximately two-thirds of the normal $\mathrm{CN}$ hand representation was taken over by dorsal hand inputs. This postinjury expansion was seen in most $\mathrm{CN}$ planes; i.e., dorsal hand representations that were at or above the upper $95 \%$ confidence interval size of normal dorsal hand representations were seen in 9 of 11 postinjury CN maps (Fig. 5).

Representations of inputs from subregions of the dorsal hand underwent variable changes in size. Expansions of the representations of the digit skin and radial (thumb) half of the dorsal hand were larger than expansions of representations of complementary regions on the proximal and ulnar (little finger) half of the dorsal hand (Fig. 6A). The smaller enlargement of the ulnar, as compared with the radial representation, likely reflects the partial denervation of the ulnar dorsal hand attributable to the ulnar nerve injury. Consistent with this, receptive fields in each postinjury $\mathrm{CN}$ map typically covered most $($ mean $=75 \%$ ) of the dorsal hand surface; however, inputs from all or most of digit 5 and/or the adjacent ulnar hand, which are commonly part of the ulnar nerve innervation territory, were usually not represented in $\mathrm{CN}$ maps (Fig. 6B). The differences in enlargements of representations of digit versus proximal hand regions are not attributable to differential denervation because the ulnar sides of both regions were denervated. Together, these findings suggest that $\mathrm{CN}$ representations of dorsal hand subregions did not enlarge uniformly, partly because of denervation gradients and partly because of other factors that remain less clear.

Several features of somatotopic organization were consistently observed in postinjury $\mathrm{CN}$ representations of the dorsal hand. (1) As described above, acute injury resulted in expression of a largely continuous postinjury dorsal hand representation. This decreased the somatotopic fracturing inherent in the normal discontinuous, patchy representation of this skin. (2) Tactile
A

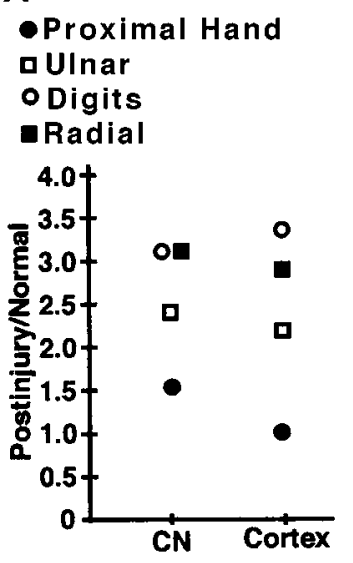

B Cuneate

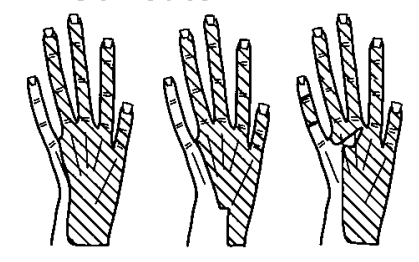

C Cortex

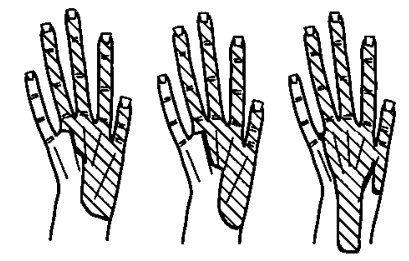

Figure 6. Analyses of $\mathrm{CN}$ and area $3 \mathrm{~b}$ representations of subregions of the dorsal hand. A, Enlargement ratios (Postinjury/Normal) for representations of distal, proximal, radial, and ulnar subregions. Note that in both the $\mathrm{CN}$ and area $3 \mathrm{~b}$, representations of distal (i.e., digit) and radial subregions had larger postinjury enlargements than proximal and ulnar subregions. $B, C$, Examples of composite receptive field areas (hatching) that were represented in each of three $\mathrm{CN}(B)$ and three area $3 \mathrm{~b}(C)$ postinjury maps. Note that (1) similar locations and extents of the dorsal hand were represented in individual maps at both levels, and (2) the ulnar edge was usually not represented (because of ulnar nerve section). See Results for further details.

inputs from the digits tended to activate neurons at more dorsal $\mathrm{CN}$ sites, whereas inputs involving more proximal locations on the back of the hand usually activated more ventral sites (Fig. $7 A-F)$. (3) Inputs from the radial half of the dorsal hand usually activated neurons at more lateral to lateroventral sites, whereas ulnar inputs usually activated more mediodorsal sites (Fig. 8A$F)$. (4) $\mathrm{CN}$ areas with inputs from different dorsal digits were represented in a partially shifted but overlapping manner. Digit 1 was represented most lateroventrally, digit 5 (when present) or digit 4 was represented most mediodorsally, and intervening digit representations overlapped in between (Fig. 9A-C). (5) Finally, postinjury $\mathrm{CN}$ somatotopic gradients for distal-proximal, radialulnar, and digit inputs were in rough register with somatotopic gradients of normal inputs from these hand parts (Figs. 7-9).

The above changes did not lead to major changes in sizes of $\mathrm{CN}$ dorsal hand receptive fields. Postinjury dorsal fields, like normal dorsal fields, involved one or more digits and/or an adjacent area on the dorsal hand (Fig. 10A,B) and occupied a mean area of $6.7 \%$ of the hand surface. This is similar to the size of normal dorsal hand fields (mean $=7.7 \%$; $t[11]=0.26, p=$ 0.80) (Fig. 11) (Xu and Wall, 1999).

\section{Forelimb and other representations}

Preinjury receptive fields on the glabrous hand occasionally shifted to forelimb locations after injury; however, the postinjury sizes of the forelimb and other representations were similar to normal [postinjury: forelimb mean $=23.4 \%(\mathrm{SD}=2.2)$ and trunk-face-hindlimb mean $=13.9 \%(\mathrm{SD}=2.1)$ of $\mathrm{CN}$ transverse area; normal: forelimb mean $=27.6 \%(\mathrm{SD}=8.1)$ and trunkface-hindlimb mean $=10.5 \%(\mathrm{SD}=4.9)$ of $\mathrm{CN}$ transverse area (Table 1)]. In addition, postinjury forelimb and other representations were in their normal lateral and medial $\mathrm{CN}$ locations and had a normal somatotopic organization, with representations of the forelimb, shoulder, neck, and face located lateral to the hand representation, and inputs from the forelimb, trunk, and proximal 


\section{Cuneate Nucleus}

\section{Postinjury}

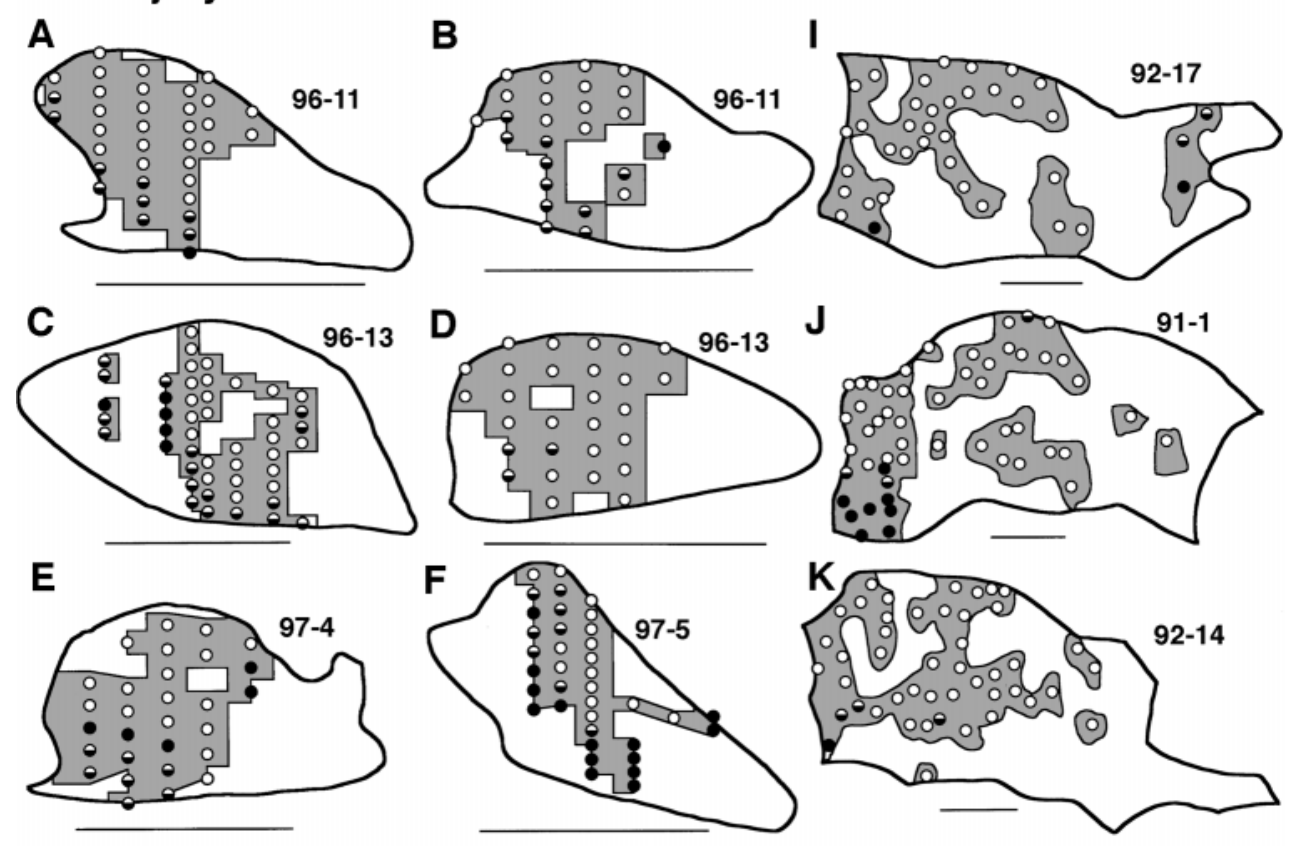

\section{Normal}

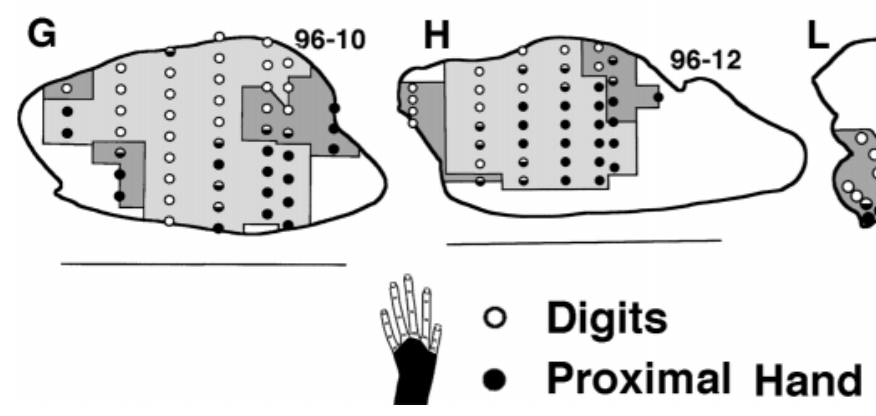

\section{Area 3b}

Figure 7. Somatotopic gradients of receptive fields on the dorsal digits and proximal dorsal hand in $\mathrm{CN}(A-H)$ and area $3 \mathrm{~b}(I-L)$ maps. $A-F$, Within postinjury $\mathrm{CN}$ dorsal hand representations (dark shading), recording sites with fields on the digits $(\bigcirc)$ typically occupied more dorsal locations, whereas sites with fields on the proximal hand $(\bullet)$ or that extended from the digits onto the proximal hand $(\ominus)$ typically occupied more ventral locations. $G$, $H$, Normal $\mathrm{CN}$ maps of the glabrous (light shading) and dorsal (dark shading) hand have a similar gradient. $I-L$, Analogous somatotopic gradients across the distalproximal dorsal hand are seen in postinjury $(I-K)$ and normal $(L)$ dorsal hand representations (dark shading) in area $3 \mathrm{~b}$. For $\mathrm{CN}$ maps, dorsal $=u p$ and medial $=$ right. Scale bar, $1 \mathrm{~mm}$. For area $3 \mathrm{~b}$ maps, anterior $=u p$, medial $=$ right . Scale bar, 1 $\mathrm{mm}$. In all maps, equal density recording sites in white areas are not indicated. hindlimb located medial to the hand representation (Fig. 12) [compare with Xu and Wall (1999)]. Taken together, these results suggest that forelimb and other nonhand tactile representations did not undergo major changes. In view of the above magnitude and consistency of changes in dorsal hand representations, these findings indicate that there was an anisotropy in CN reorganization mechanisms that favored expansion of dorsal hand over forelimb or other, cutaneous inputs.

\section{Cutaneously unresponsive areas}

As indicated above, injury led to a loss of low-threshold cutaneous responsiveness at some $\mathrm{CN}$ recording sites. Normally, a mean of $8.8 \%$ of the $\mathrm{CN}$ transverse plane area is occupied by sites that are not responsive to low-threshold tactile stimulation of the skin (Table 1). These sites are located outside the hand representation, usually near the $\mathrm{CN}$ borders. After injury, cutaneously unresponsive areas enlarged to a mean of $27.6 \%$ of the $\mathrm{CN}$ transverse area, an increment of $18.8 \%$ above normal $(t[11]=3.3$, $p=0.008$ ) (Table 1). This increment involved CN locations where the glabrous hand is normally represented and locations around postinjury representations of the dorsal hand (Figs. 1, 12). Given that the normal hand representation occupies a mean area of $53.1 \%$ of the $\mathrm{CN}$ transverse area (see above), this increment is equivalent to $\sim 35.4 \%$ (i.e., 18.8/53.1) of the normal $\mathrm{CN}$ hand representation. Although neurons at these sites were not responsive to tactile stimulation of the skin, they were often responsive to harder tap stimuli, to stimulation of deep tissues, and/or to movement of joints. Taken together with the above results on the dorsal hand and forelimb representations, these findings suggest that, after injury, approximately two-thirds of the normal $\mathrm{CN}$ hand representation was activated by dorsal hand inputs, and approximately one-third lost responsiveness to low threshold cutaneous inputs. In contrast, representations of tactile inputs from the forelimb and other body parts either did not change or had small, less consistent changes.

\section{Relationships between $\mathrm{CN}$ and area $3 \mathrm{~b}$ postinjury organization}

Immediate postinjury changes have been defined in area $3 \mathrm{~b}$ after this injury (Kolarik et al., 1994), but no attempts have been made to relate acute cortical and subcortical organization. As summarized next, there were interesting similarities, and differences, in postinjury organization in the $\mathrm{CN}$ and area $3 \mathrm{~b}$ (Table 2).

\section{Similarities in $\mathbf{C N}$ and area $\mathbf{3 b}$ organization}

Time course for changes

At both $\mathrm{CN}$ and area $3 \mathrm{~b}$ levels, initial changes in receptive fields were seen within minutes, and related changes in representations 


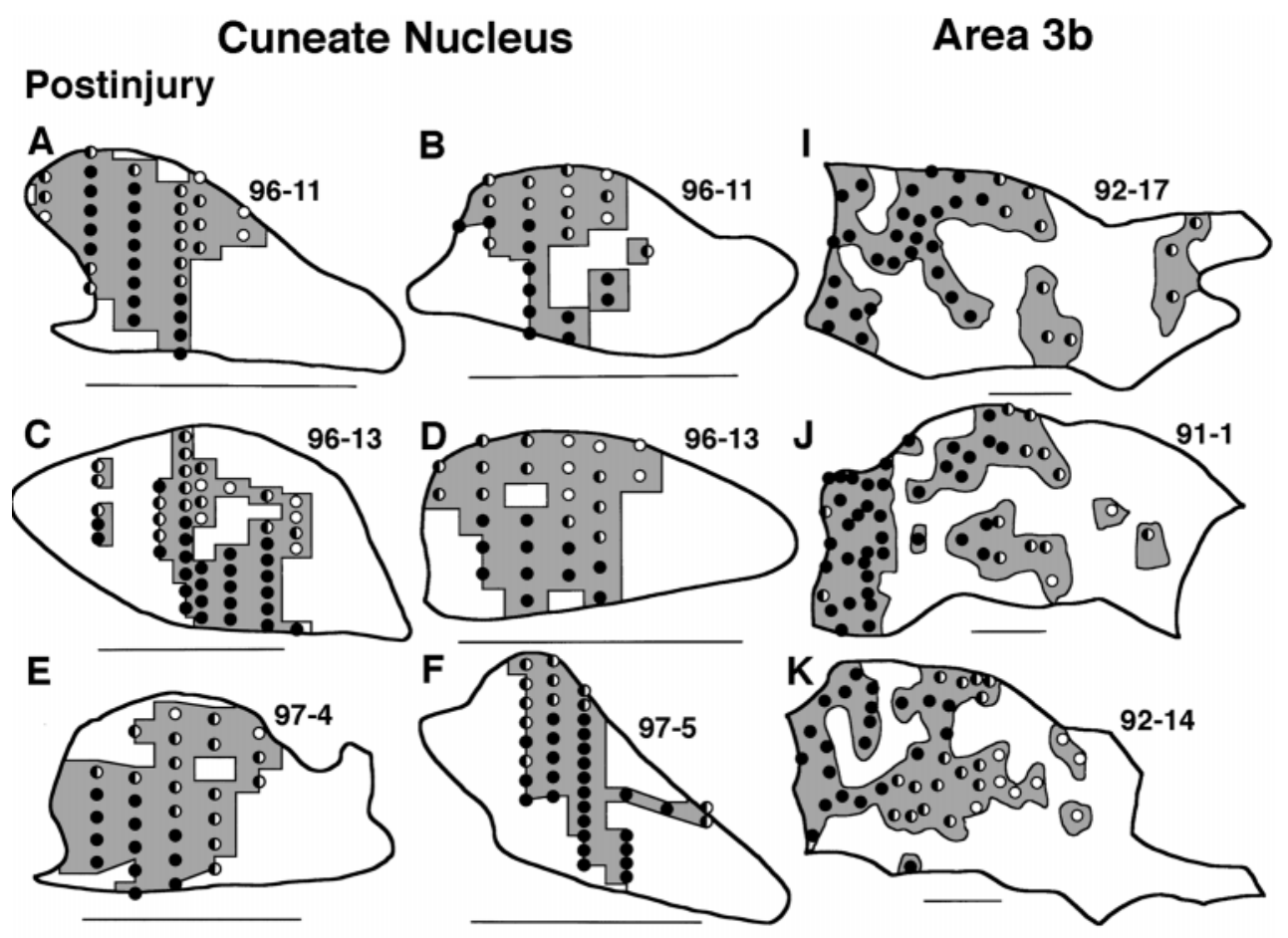

Figure 8. Somatotopic gradients of receptive fields on the radial and ulnar dorsal hand in $\mathrm{CN}(A-H)$ and area $3 \mathrm{~b}$ $(I-L)$ maps. $A-F$, Within postinjury $\mathrm{CN}$ dorsal hand representations (dark shading), recording sites with fields on the radial hand $(\mathbf{0})$ typically occupied more lateral to lateroventral locations, whereas sites with fields on the ulnar hand $(\bigcirc)$ or that extended from the radial to ulnar hand $(\mathbf{O})$ typically occupied more mediodorsal locations. $G, H$, Normal CN maps of the glabrous (light shading) and dorsal (dark shading) hand have a similar gradient. $I-L$, Analogous somatotopic gradients across the radialulnar hand are seen in postinjury $(I-K)$ and normal $(L)$ dorsal hand representations (dark shading) in area 3b. For $\mathrm{CN}$ maps, dorsal $=u p$ and medial $=$ right . Scale bar, $1 \mathrm{~mm}$. For area $3 \mathrm{~b}$ maps, anterior $=u p$ and medial $=$ right. Scale bar, $1 \mathrm{~mm}$.

\section{Normal}

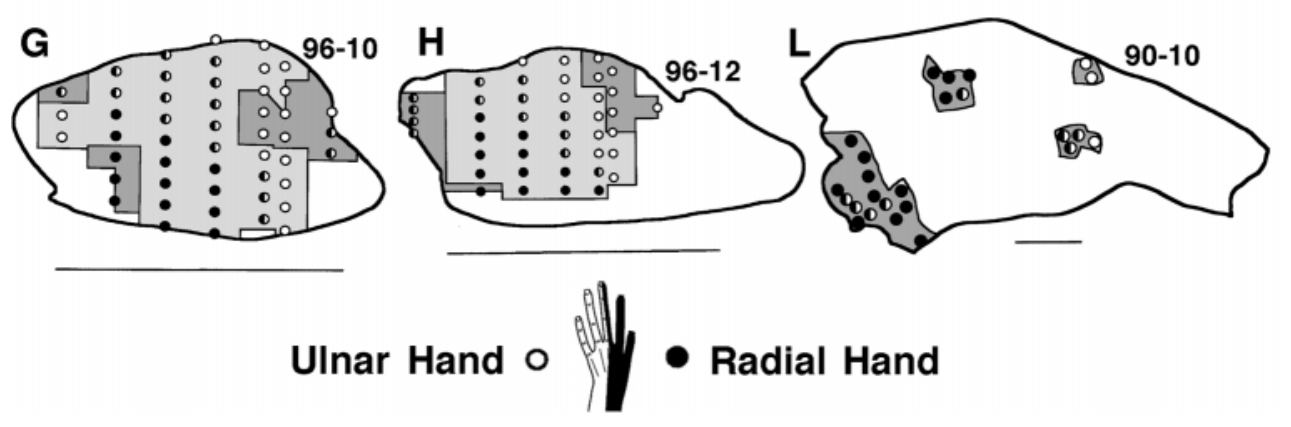

were apparent within hours after this injury (Fig. 1) [and see Kolarik et al. (1994)]. These findings suggest that initial CN and area 3 b functional changes occur concurrently (Table 2).

\section{Hand receptive fields}

At both levels, the main postinjury change in tactile receptive fields involved shifts from preinjury glabrous to postinjury dorsal hand locations. Postinjury dorsal receptive fields occupied similar combinations of hand regions at both levels (Fig. 10B,C).

\section{Hand representations}

Postinjury $\mathrm{CN}$ and area $3 \mathrm{~b}$ representations of the hand were similar in several ways (Table 2). First, at both levels, enlargement of the normally small dorsal hand representation was the predominant change. Second, similar locations and extents of the dorsal hand were represented in the postinjury hand representation at each level; in addition, each level had relatively larger expansions of representations of the digits and radial dorsal hand than of the complementary proximal and ulnar hand (Fig. 6). Third, postinjury dorsal hand representations at both levels had analogous somatotopic gradients. This was reflected, for example, by the distributions of $\mathrm{CN}$ and area $3 \mathrm{~b}$ recording sites with inputs from proximal-digit (Fig. 7, compare $A-F, I-K$ ) and radial-ulnar (e.g.,
Fig. 8A-F vs I-K) hand regions. Finally, both levels had partially shifted and overlapping postinjury representations of dorsal digits that were in rough register with normal glabrous digit representations (Fig. 9). Taken together, these similarities suggest that some postinjury features of $\mathrm{CN}$ dorsal hand representations were consistently preserved in area $3 b$ (Table 2).

\section{Forelimb representations}

This injury resulted in a small expansion of forelimb inputs into a mean area of $5 \%$ of the area $3 \mathrm{~b}$ hand representation (Kolarik et al., 1994). In the $\mathrm{CN}$, receptive fields occasionally shifted from glabrous hand to forelimb locations; however, postinjury $\mathrm{CN}$ representations of the forelimb were not larger than normal (see above). Given this and the small extent of the area $3 \mathrm{~b}$ changes, it would appear that any differences in enlargements of $\mathrm{CN}$ and area $3 b$ forelimb representations were small. Thus, despite similar adjacencies of forelimb and hand inputs at both levels, forelimb representations did not enlarge like dorsal hand representations (Table 2). This suggests that $\mathrm{CN}$ and area $3 \mathrm{~b}$ reorganizations shared a similar anisotropy that led to larger expansions of dorsal hand inputs than forelimb inputs. 


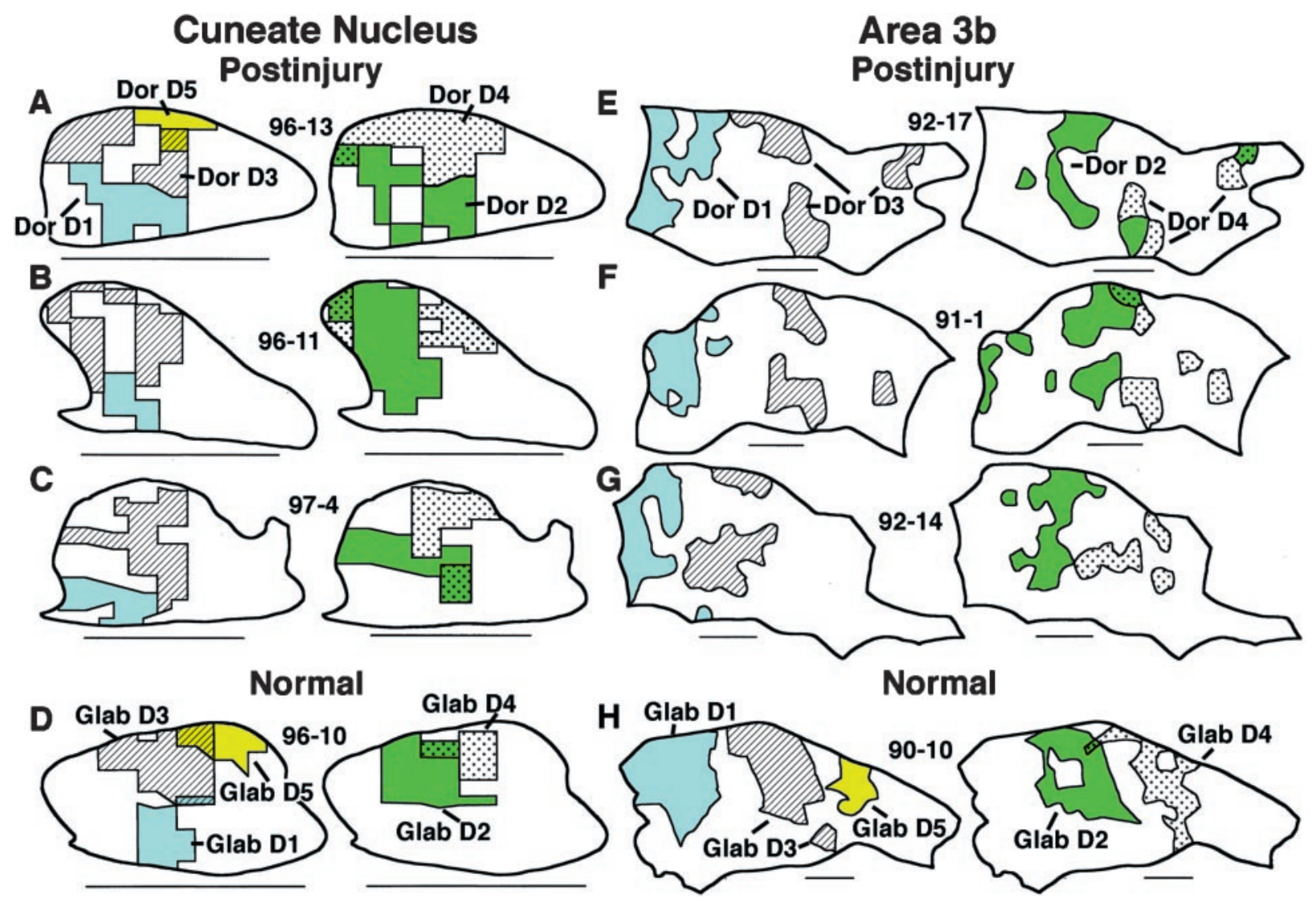

Figure 9. Somatotopic organization of digit representations in the $\mathrm{CN}(\mathrm{A}-\mathrm{D})$ and area $3 \mathrm{~b}(E-H)$. A-C, Shading and labeling of areas in three postinjury $\mathrm{CN}$ maps indicate postinjury representations of dorsal digits (Dor D) 1,3, and, where seen, 5 in the first column, and of dorsal digits 2 and 4 in the second column. Note (1) the partially shifted and overlapping locations of these representations from D1 lateroventrally to D5 (or 4 ) mediodorsally and (2) their rough in-register relation to normal glabrous digit representations $(D) . E-G$, Shading and labeling of areas in three postinjury area $3 \mathrm{~b}$ maps indicate postinjury representations of dorsal digits 1 and 3 in the third column and 2 and 4 in the fourth column. Note that, similar to the CN, postinjury area $3 \mathrm{~b}$ representations of dorsal digits occupied areas that were partially shifted and overlapping from $D 1$ laterally to $D 4$ medially and were in rough register with normal glabrous digit representations $(H)$. For $\mathrm{CN}$ maps, dorsal $=u p$ and medial $=$ right. Scale bar, $1 \mathrm{~mm}$. For area $3 \mathrm{~b}$ maps, anterior $=u p$ and medial $=$ right. Scale bar, $1 \mathrm{~mm}$.

\section{Differences in $\mathrm{CN}$ and area $3 \mathrm{~b}$ organization}

Sizes of hand receptive fields

The size distributions of postinjury $\mathrm{CN}$ and area $3 \mathrm{~b}$ dorsal hand fields overlapped; however, area $3 \mathrm{~b}$ fields were smaller in terms of mean (3b: $4 \%$; CN: $6.7 \% ; t[7]=2.7 ; p<0.03$ ), mode (3b: $2 \%$; $\mathrm{CN}: 5 \%$ ), and upper $95 \%$ confidence interval (3b: $11.6 \%$; $\mathrm{CN}$ : $16.3 \%$ ) sizes (Fig. 13). In addition, area $3 \mathrm{~b}$ had a lower incidence of multidigit dorsal fields ( $3 \mathrm{~b}$ : mean $=23.9 \%$; $\mathrm{CN}$ : mean $=48 \%$; $t[7]=3.8 ; p<0.007)$. Taken together, these findings indicate that postinjury fields on the dorsal hand tend to be smaller in area $3 \mathrm{~b}$ (Table 2). This suggests that postinjury tactile fields undergo sharpening transformations between the $\mathrm{CN}$ and area $3 \mathrm{~b}$.

\section{Hand representations}

Postinjury $\mathrm{CN}$ and area $3 \mathrm{~b}$ dorsal hand representations differed in the following ways (Table 2). First, representations in area $3 b$ were consistently discontinuous, occupying three to six patches, whereas $\mathrm{CN}$ representations were more continuous (Fig. 7, compare $I-K, A-F)$. Under normal conditions, the dorsal hand representation is discontinuous at both levels (Fig. $7 G, H, L$ ); thus, injury resulted in greater $\mathrm{CN}$ than area $3 \mathrm{~b}$ merging of the normal discontinuous representation of the dorsal hand (Table 2). Second, a larger percentage of the hand map was activated by dorsal hand inputs in the $\mathrm{CN}$ than in area $3 \mathrm{~b}$. The area $3 \mathrm{~b}$ representation of the dorsal hand normally occupies a mean area of $15 \%$ of the area $3 \mathrm{~b}$ hand representation, whereas the $\mathrm{CN}$ representation normally occupies a mean area of $27 \%$ of the $\mathrm{CN}$ hand representation (Fig. 5). After injury, the mean dorsal hand representations expanded by approximately 2.5 times at both levels, which resulted in these inputs being represented in a mean area equal to $66 \%$ of the normal $\mathrm{CN}$ hand map area but only $37 \%$ of the normal area $3 \mathrm{~b}$ hand map area (Fig. 5). Thus, postinjury dorsal hand inputs in the $\mathrm{CN}$ activated a larger percentage of the hand map space than the same inputs in cortex (Table 2). With few exceptions, this difference was consistently seen. For example, 9 of $11 \mathrm{CN}$ postinjury dorsal hand representations were larger than the largest postinjury representation in area $3 \mathrm{~b}$ (Fig. 5). These findings suggest that relatively large and continuous postinjury $\mathrm{CN}$ representations of the dorsal hand were attenuated or incompletely expressed as relatively smaller, less continuous representations in area $3 \mathrm{~b}$. Thus, some features of $\mathrm{CN}$ hand representations were transformed before being expressed in area $3 \mathrm{~b}$.

\section{Cutaneously unresponsive areas}

Denervation of the glabrous hand resulted in acute losses of tactile responses at both levels; however, different extents of loss occurred at each level. Neurons at all recording sites in the area $3 b$ hand representation are normally responsive to tactile inputs, 
A Cuneate Normal
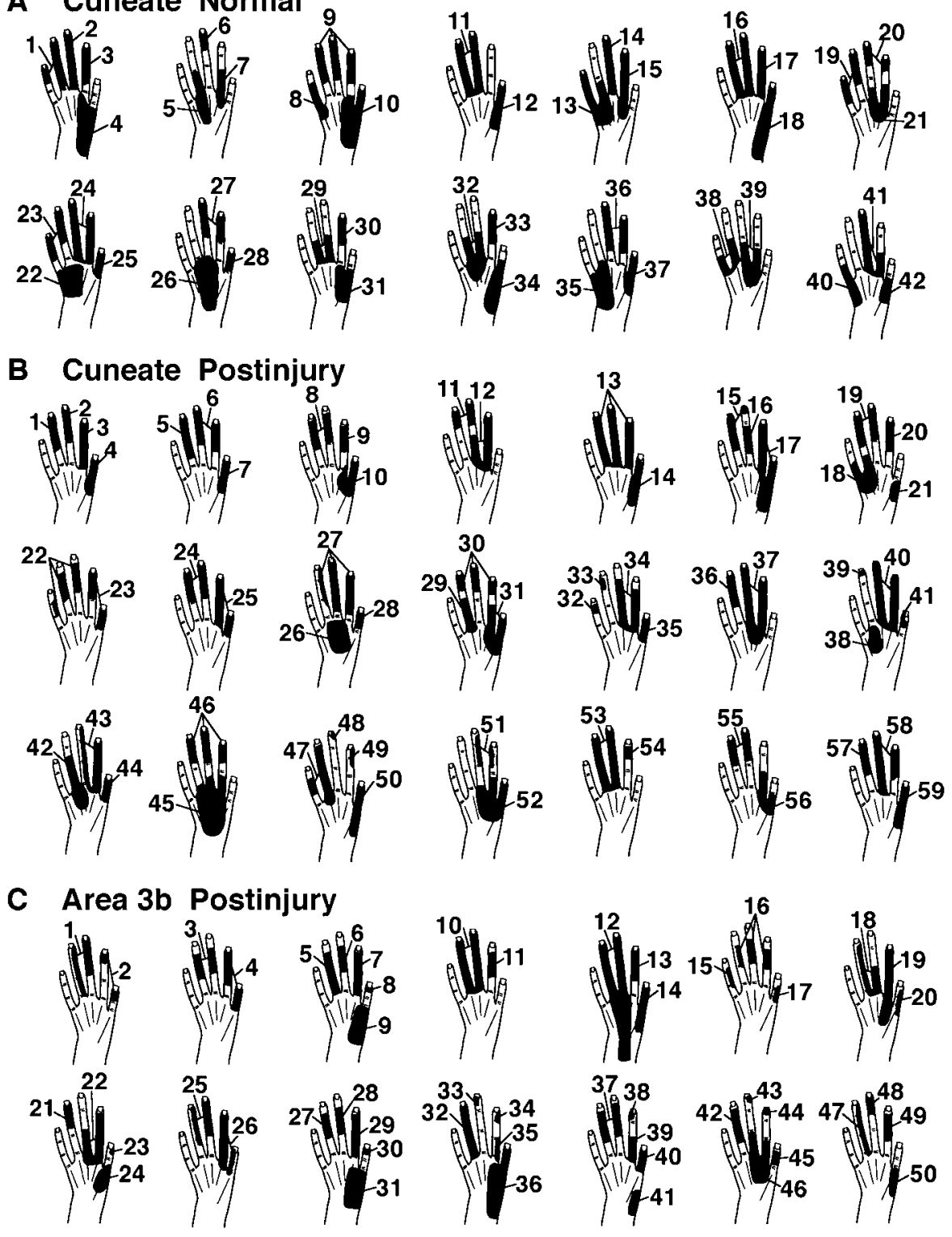

whereas after injury a mean area of $58.5 \%(\mathrm{SD}=8.3)$ of this representation became unresponsive to tactile inputs (Kolarik et al., 1994). In contrast, the $\mathrm{CN}$ had postinjury increments in tactilely unresponsive sites that involved a mean area equal to $35.4 \%$ of the normal $\mathrm{CN}$ hand map (see above), indicating that $\mathrm{CN}$ maps underwent less extensive losses of tactile responsiveness than area $3 \mathrm{~b}$ maps (Table 2). These results further support the view that changes in $\mathrm{CN}$ tactile input organization were not fully expressed in area $3 b$.

\section{DISCUSSION}

The results suggest that the $\mathrm{CN}$ of adult monkeys undergoes rapid functional changes after hand injury and that concurrent changes in area $3 \mathrm{~b}$ reflect preservations and transformations of $\mathrm{CN}$ changes. These findings, their limitations, and their significance are discussed in turn.

\section{How do features of $\mathrm{CN}$ tactile input organization change immediately after injury?}

Several CN changes emerged after this injury. First, CN neurons lost glabrous receptive fields and within minutes acquired dorsal hand fields or, less frequently, lost tactile responsiveness. Second, the dorsal hand representation enlarged, became more continuous, and occupied $\mathrm{CN}$ locations where the glabrous hand is normally represented. Third, enlarged dorsal hand representations were somatotopically organized, with distal-to-proximal inputs activating dorsal-to-ventral $\mathrm{CN}$ locations, radial-to-ulnar inputs activating lateral-to-medial locations, and representations of dorsal digits activating partially shifted but overlapping areas that were in rough register with normal representations of glabrous digits. Fourth, other representations did not undergo major changes, indicating that there were anisotropies in the capacities of hand and other tactile inputs to reorganize. Finally, this injury deprived $\sim 74 \%$ of the $\mathrm{CN}$ hand map of normal tactile inputs; approximately two-thirds of the map became driven by radial nerve inputs from the dorsal hand, whereas about one-third lost tactile responsiveness. Thus, $\mathrm{CN}$ tactile responsiveness, receptive fields, somatotopic organization, and properties of representations (i.e., location, size, continuity) clearly changed within minutes to hours after this injury. We add the cautionary note that these changes were defined in a limited number of $\mathrm{CN}$ maps; 


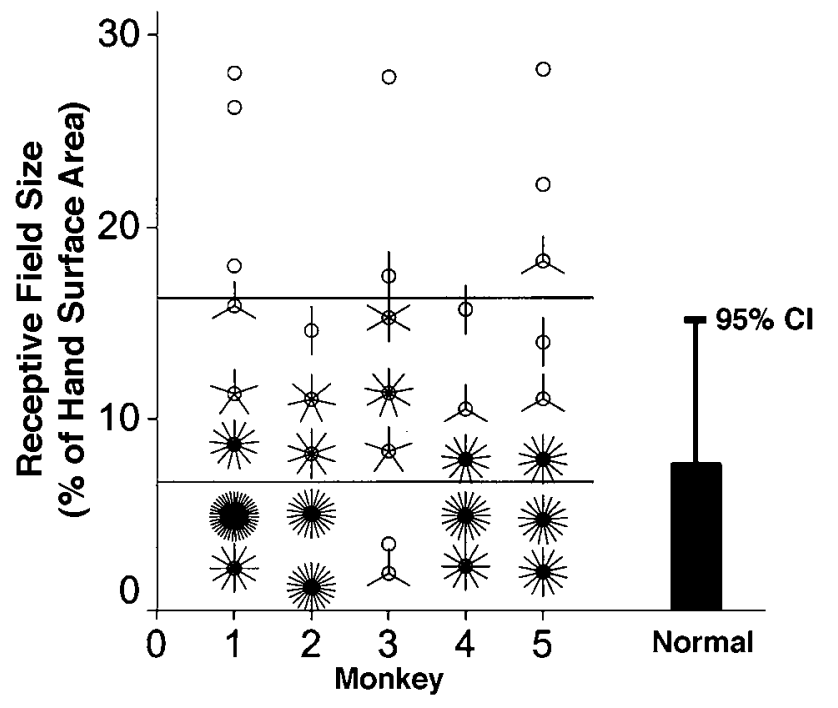

Figure 11. Postinjury and normal CN receptive fields on the dorsal hand were similar in size. Flower petal graph on the left shows sizes of all postinjury dorsal hand receptive fields in five monkeys (1 petal in each flower $=1$ receptive field). The bottom line indicates mean size, and the top line indicates the upper $95 \%$ confidence interval distinguishing the main part of the sample from outlier fields. The histogram on the right indicates mean and $95 \%$ confidence interval $(C I)$ sizes for normal dorsal hand fields from 10 monkeys.

however, they appeared consistently in maps of different monkeys. These findings extend previous results that indicate that $\mathrm{CN}$ hand representations in monkeys rapidly change after injury $(\mathrm{Xu}$ and Wall, 1997a).

There is substantial disagreement about how acute peripheral manipulations in adults affect $\mathrm{CN}$ organization. In this regard, acute loss of $\mathrm{CN}$ tactile responses, but no receptive field reorganization, occurred after lidocaine block of nerves to fingers of raccoons (Northgrave and Rasmusson, 1996) and after cold block of forepaw nerves in cats (Zhang and Rowe, 1997). In the only previous study of acute injury, Zhang and Rowe (1997) tested several $\mathrm{CN}$ neurons after section of forepaw nerves and got similar negative results. These findings are consistent with losses of tactile responses in the present study. In contrast, Pettit and Schwark $(1993,1996)$ assessed CN tactile responses after subcutaneous forepaw injections of lidocaine or capsaicin and found rapid field changes in all tested neurons. These changes are consistent with the present shifts in fields [for similar mixed results in the gracile and trigeminal nuclei, see Dostrovsky et al. (1976); Millar et al. (1976); McMahon and Wall (1983); Waite (1984); Panetsos et al. (1995, 1997); Faggin et al. (1997)].

There currently is no explanation for the above differences in results. Taken together with other data, the present findings suggest that one factor in acute $\mathrm{CN}$ reorganization is how the manipulation interacts with residual $\mathrm{CN}$ afferents. In this regard, the present findings of rapid glabrous-to-dorsal field shifts correlate with anatomical and functional findings that dorsal and glabrous afferents normally terminate in closely adjacent $\mathrm{CN} \mathrm{CO}$ patches (Florence et al., 1991; Xu and Wall, 1999). Moreover, preliminary findings further indicate that terminations of dorsal hand afferents span larger extents of the $\mathrm{CN}$ than normal functional representations of these afferents, thus suggesting that some dorsal afferents are normally not functionally expressed (Xu and Wall, 1997b). In contrast, the lack of rapid field changes after blockade of inputs from a finger in raccoons correlates with
A
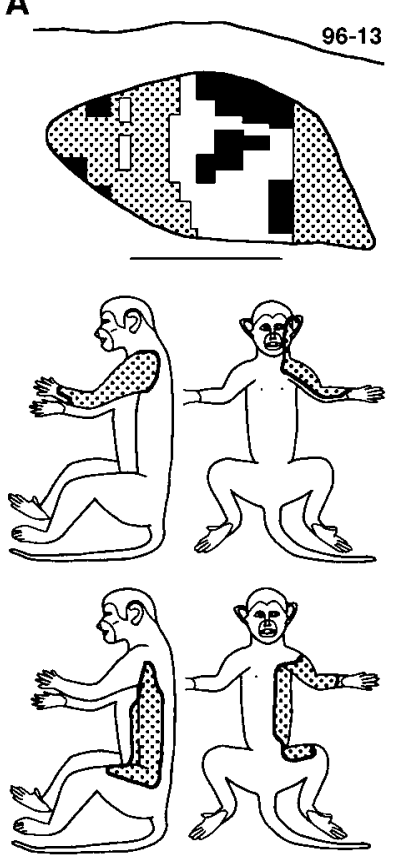

B
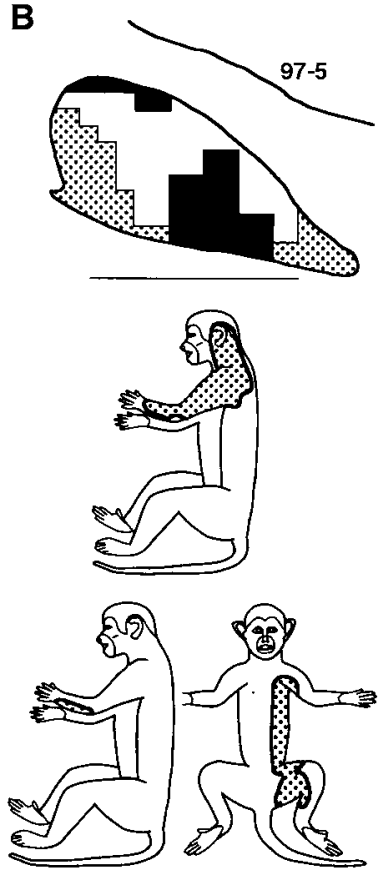

Figure 12. Postinjury $\mathrm{CN}$ representations of tactile inputs from the forelimb-trunk-face in two maps $(A, B)$. Top, Camera lucida tracings of two CNs. Dorsal $=u p$; medial $=$ right . Scale bar, $1 \mathrm{~mm}$. Stippling indicates $\mathrm{CN}$ areas that contained recording sites with forelimb, trunk, and face receptive fields. These areas are located lateral and medial to the dorsal hand representation (white) and adjacent to areas with recording sites that were not responsive to tactile stimulation of the skin (black). Middle, Composite of the receptive field areas of all recording sites with forelimbtrunk-face fields that were located in the area lateral to the hand representation for the above $\mathrm{CN}$. In each case, note that this skin included the forelimb, shoulder, neck, and face. Bottom, Composite of the receptive field areas of all recording sites with forelimb-trunk fields that were located medial to the hand representation for the above $\mathrm{CN}$. In each case, note that this skin included the forelimb, trunk, and proximal hindlimb.

anatomical findings that afferents from each finger terminate in separate CN compartments (Rasmusson, 1988; Northgrave and Rasmusson, 1996). Thus, injury of glabrous inputs in monkeys may leave normally unexpressed dorsal inputs as available substrates for CN synaptic change mechanisms, whereas blockade of inputs from a finger in raccoons may leave no comparable substrates. Other factors, including the nature of the peripheral manipulations, may also contribute (Northgrave and Rasmusson, 1996; Zhang and Rowe, 1997).

The present findings provide insight into normal mechanisms of $\mathrm{CN}$ processing of hand inputs. For example, the rapid field shifts suggest that normal glabrous fields are not "hardwired" but are constructed physiologically by sharpening mechanisms that suppress dorsal hand inputs. At the scale of representations, the replacement of the representation of the glabrous surface with a colocalized large, continuous, somatotopic, and roughly inregister representation of the dorsal surface suggests that $\mathrm{CN}$ substrates contain overlapping representations of both surfaces that are in a flexible state but normally set to express the glabrous representation. There is a recognition that the $\mathrm{CN}$ normally transforms, rather than simply relays, tactile information from the hand; however, these transformations are not understood. The present findings suggest that $\mathrm{CN}$ transformations sharpen receptive fields and, on a larger scale, selectively promote (e.g., glabrous) and suppress (e.g., dorsal) full expression of representations. 
Table 2. Similarities and differences in acute postinjury $\mathrm{CN}$ and area $3 \mathrm{~b}$ organization

\begin{tabular}{|c|c|c|}
\hline & Similarity & Difference \\
\hline Time course & Initial changes within minutes and apparent for hours & \\
\hline \multirow[t]{2}{*}{ Tactile receptive fields } & $\begin{array}{l}\text { Changes from glabrous hand fields to dorsal hand } \\
\text { fields }\end{array}$ & Area $3 \mathrm{~b}$ fields are smaller \\
\hline & & Fewer area $3 b$ multidigit fields \\
\hline \multirow[t]{4}{*}{ Dorsal hand representations } & $\begin{array}{l}\text { Changes in dorsal hand representations were } \\
\text { predominant tactile representation changes }\end{array}$ & $\begin{array}{l}\text { Largely continuous in } \mathrm{CN} \text {, but discontinuous } \\
\text { in area } 3 \mathrm{~b}\end{array}$ \\
\hline & Involvement of similar extents and locations of skin & $\begin{array}{l}\text { Larger percentage of hand map in the } \mathrm{CN} \\
\text { than in area } 3 \mathrm{~b}\end{array}$ \\
\hline & Larger enlargements of digit and radial inputs & \\
\hline & $\begin{array}{l}\text { Digit representations in a partially shifted and } \\
\text { overlapping sequence that was in register with } \\
\text { normal somatotopic gradients }\end{array}$ & \\
\hline Forelimb representations & No major expansion of forelimb representations & \\
\hline Cutaneously unresponsive area & & $\begin{array}{l}\text { Larger percentage of hand map in area } 3 b \\
\text { than in the } \mathrm{CN}\end{array}$ \\
\hline
\end{tabular}

\section{How are initial changes in $\mathrm{CN}$ and area $3 \mathrm{~b}$ hand representations related?}

Few studies have compared brainstem and cortical organization after acute peripheral manipulations in adults, and no consensus has emerged from the findings. In the only previous study involving the $\mathrm{CN}$, finger denervations in raccoons caused acute changes in somatosensory (SI) cortex and thalamus but not in the $\mathrm{CN}$ (Turnbull and Rasmusson, 1990; Rasmusson et al., 1993; Northgrave and Rasmusson, 1996). In contrast, Panetsos et al. (1995) recorded simultaneous changes in receptive fields in the gracile nucleus and SI cortex of rats after lidocaine blockades of hindpaw inputs. Similarities observed in receptive field changes at paired gracile and cortical sites suggested that brainstem changes were preserved in cortex. More recently, Faggin et al. (1997) [also see Nicolelis (1997)] observed new whisker responses from simultaneously recorded sites in the trigeminal nucleus and SI cortex after lidocaine injections in face regions of rats. They also observed mismatches in the sets of whiskers that elicited new responses at each level, suggesting that cortical changes were not just preservations of brainstem changes.

The present findings indicate that $\mathrm{CN}$ and area $3 \mathrm{~b}$ postinjury changes were similar in some respects but different in others (Table 2). Similarities included (1) the time course of field shifts, (2) expansions of normally small dorsal representations into glabrous representation locations in a somatotopic manner, (3) involvement of afferents from comparable regions of the dorsal hand, and (4) anisotropies in the capacity of hand versus other inputs to reorganize. Organization at $\mathrm{CN}$ and area $3 \mathrm{~b}$ levels also differed in that in the CN (1) dorsal hand fields were larger, (2) representations of the dorsal hand were more continuously distributed across locations normally having glabrous inputs and involved larger extents of the hand map, and (3) cutaneously unresponsive areas occupied smaller extents of the hand map. Again, we add the cautionary note that these findings are based on limited numbers of maps.

In primates, ascending connections through the $\mathrm{CN}$ and ventroposterolateral nucleus are essential for normal tactile driving of area 3 b receptive fields on the hand (Jain et al., 1997; Jones et al., 1997). This cortical dependence on lemniscal inputs does not appear to be reciprocated; preliminary results suggest that normal tactile fields and hand map organization are maintained in the
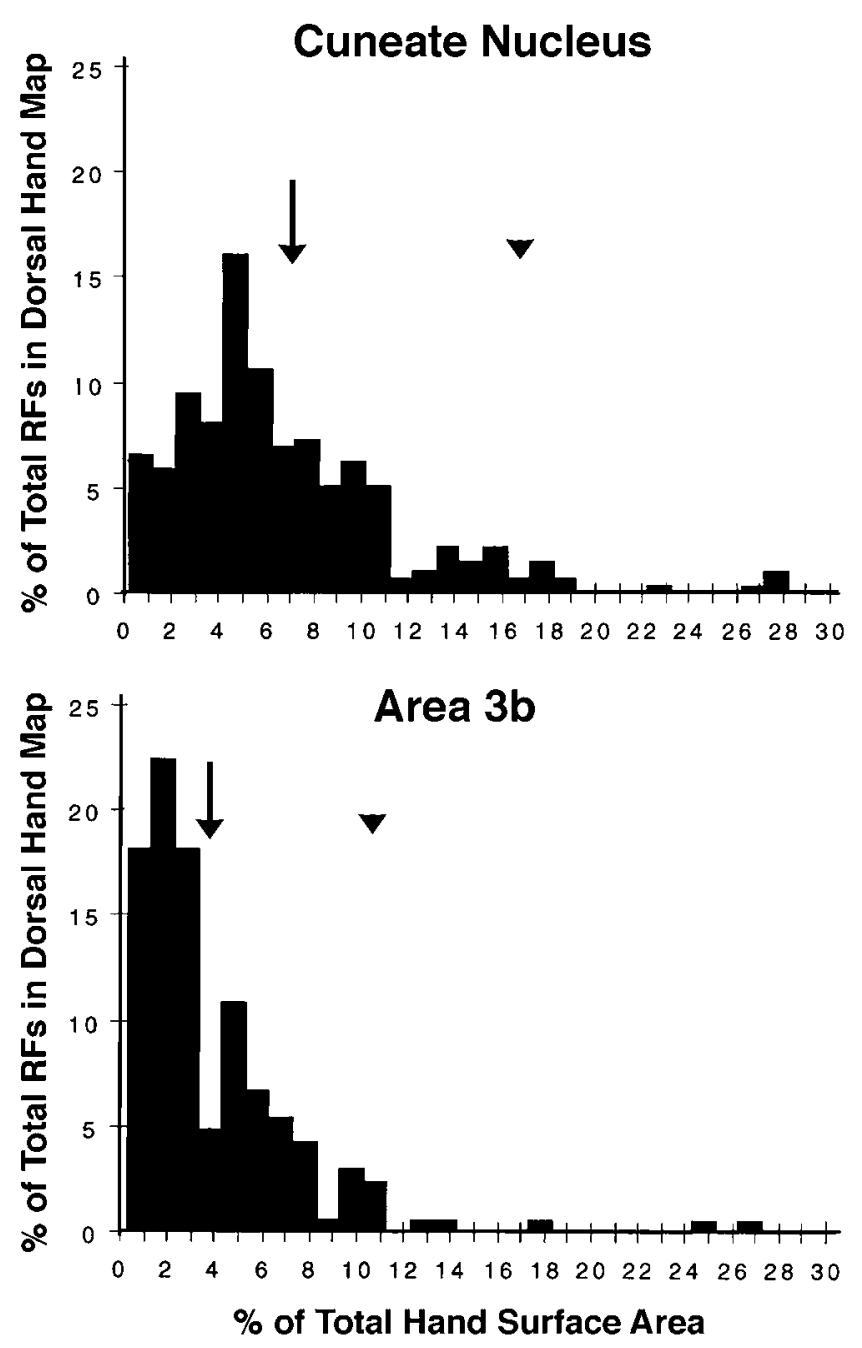

Figure 13. Histograms of the sizes of postinjury dorsal hand receptive fields in the $\mathrm{CN}(t o p)$ and area $3 \mathrm{~b}$ (bottom). The distributions of $\mathrm{CN}$ and area $3 b$ fields overlap; however, area $3 b$ fields were smaller in terms of mean (arrows), mode $(\mathrm{CN}=5 \%$, area $3 \mathrm{~b}=2 \%)$, and upper $95 \%$ confidence (arrowheads) sizes. See Results for details. 
$\mathrm{CN}$ of monkeys after acute lesions of area $3 \mathrm{~b}$ and parietal cortex (our unpublished observations). Similarly, with or without somatosensory cortex, $\mathrm{CN}$ receptive fields undergo comparable rapid changes after peripheral denervation (Pettit and Schwark, 1993). Thus, tactile driving in area $3 \mathrm{~b}$ is dependent on $\mathrm{CN}$ driving, which in turn is predominantly dependent on ascending inputs.

Given this view, our interpretation is that the similarities in $\mathrm{CN}$ and area $3 \mathrm{~b}$ changes reflect partial preservations of $\mathrm{CN}$ changes in area $3 b$ and that rapid area $3 b$ reorganization partly reflects mechanisms that operate from a distance in the CN. The sharpening of receptive fields, different spatial properties of the dorsal hand representations (size, location, continuity), and differences in tactile unresponsiveness further suggest that area $3 \mathrm{~b}$ changes are not simply copies of $\mathrm{CN}$ changes. Our interpretation is that these differences reflect supra-CN (thalamic and cortical) transformations that result in suppression or incomplete reexpression of $\mathrm{CN}$ reorganization.

What mechanisms contribute to these multilevel changes? Calford and Tweedale (1991) proposed that acute area $3 b$ reorganization after peripheral deafferentation reflects release of central inhibition that is triggered by changes in sensory afferent activity; however, the level(s) of the neuraxis where release mechanisms operated remained unclear because analysis was restricted to area 3b. From CN data, Pettit and Schwark (1993, 1996) subsequently suggested that changes in afferent activity trigger inhibition release in the CN (see also Lue et al., 1996; Panetsos et al., 1997). The present findings are consistent with peripherally triggered release of central inhibition; in addition, the findings suggest that release of inhibition is graded at $\mathrm{CN}$ and higher levels, being initially greater in the $\mathrm{CN}$ than in area $3 \mathrm{~b}$. This could account, for example, for field sharpening between the $\mathrm{CN}$ and area $3 \mathrm{~b}$ and for concurrent but more limited area $3 \mathrm{~b}$ enlargements of dorsal hand representations. Thus, a maintained greater, i.e., initially smaller, release of inhibition at higher neuraxis levels may partially attenuate $\mathrm{CN}$ mechanisms of change [for analogous developmental consequences after neonatal injury in rats see Stojic et al. (1998)]. In addition to release of inhibition, further findings suggest that sensitization (increased excitation), perhaps via mechanisms like those acting acutely in the spinal cord (Lin et al., 1997; Liu et al., 1997; Ma and Woolf, 1997), and complex bottom-up (e.g., spinothalamic) and top-down (e.g., corticofugal) interactions are also likely to contribute (Dykes, 1997; Dykes and Craig, 1998; Ergenzinger et al., 1998).

\section{REFERENCES}

Calford MB, Tweedale R (1991) Immediate expansion of receptive fields of neurons in area $3 \mathrm{~b}$ of macaque monkeys after digit denervation. Somatosen Mot Res 8:249-260.

Dostrovsky JO, Millar J, Wall PD (1976) The immediate shift of afferent drive of dorsal column nucleus cells following deafferentation: a comparison of acute and chronic deafferentation in gracile nucleus and spinal cord. Exp Neurol 52:480-495.

Dykes RW (1997) Mechanisms controlling neuronal plasticity in somatosensory cortex. Can J Physiol Pharmacol 75:535-545.

Dykes RW, Craig AD (1998) Control of size and excitability of mechanosensory receptive fields in dorsal column nuclei by homolateral dorsal horn neurons. J Neurophysiol 80:120-129.

Ergenzinger ER, Glasier MM, Hahm JO, Pons TP (1998) Cortically induced thalamic plasticity in the primate somatosensory system. Nature Neurosci 3:226-229.

Faggin BM, Nguyen KT, Nicolelis MAL (1997) Immediate and simultaneous sensory reorganization at cortical and subcortical levels of the somatosensory system. Proc Natl Acad Sci USA 94:9428-9433.
Florence SL, Wall JT, Kaas JH (1991) Central projections from the skin of the hand in squirrel monkeys. J Comp Neurol 311:563-578.

Florence SL, Jain N, Kaas JH (1997) Plasticity of somatosensory cortex in primates. Semin Neurosci 9:3-12.

Florence SL, Taub HB, Kaas JH (1998) Large-scale sprouting of cortical connections after peripheral injury in adult macaque monkeys. Science 282:1117-1121.

Jain N, Catania KC, Kaas JH (1997) Deactivation and reactivation of somatosensory cortex after dorsal spinal cord injury. Nature 386:495-498.

Jones EG, Pons TP (1998) Thalamic and brainstem contributions to largescale plasticity of primate somatosensory cortex. Science 282:1121-1125.

Jones EG, Manger PR, Woods TM (1997) Maintenance of a somatotopic cortical map in the face of diminishing thalamocortical inputs. Proc Natl Acad Sci USA 94:11003-11007.

Kolarik RC, Rasey SK, Wall JT (1994) The consistency, extent, and locations of early-onset changes in cortical nerve dominance aggregates following injury of nerves to primate hands. J Neurosci 14:4269-4288.

Lin Q, Peng YB, Wu J, Willis WD (1997) Involvement of cGMP in nociceptive processing by and sensitization of spinothalamic neurons in primates. J Neurosci 17:3293-3302.

Liu H, Mantyh PW, Basbaum AI (1997) NMDA-receptor regulation of substance $P$ release from primary afferent nociceptors. Nature 386:721-724.

Lue JH, Jiang-Shieh YF, Shieh JY, Wen CY (1996) The synaptic interrelationships between primary afferent terminals, cuneothalamic relay neurons and GABA-immunoreactive boutons in the rat cuneate nucleus. Neurosci Res 24:363-371.

Ma Q-P, Woolf CJ (1997) Tachykinin $\mathrm{NK}_{1}$ receptor antagonist RP67580 attenuates progressive hypersensitivity of flexor reflex during experimental inflammation in rats. Eur J Pharmacol 322:165-171.

McMahon SB, Wall PD (1983) Plasticity in the nucleus gracilis of the rat. Exp Neurol 80:195-207.

Merzenich MM, Kaas JH, Wall JT, Sur M, Nelson RJ, Felleman DJ (1983) Progression of change following median nerve section in the cortical representation of the hand in areas $3 \mathrm{~b}$ and 1 in adult owl and squirrel monkeys. Neuroscience 10:639-665.

Merzenich MM, Nelson RJ, Kaas JH, Stryker MP, Jenkins WM, Zook JM, Cynader MS, Schoppmann A (1987) Variability in hand surface representations in areas $3 \mathrm{~b}$ and 1 in adult owl and squirrel monkeys. J Comp Neurol 258:281-296.

Millar J, Basbaum AI, Wall PD (1976) Restructuring of the somatotopic map and appearance of abnormal neuronal activity in the gracile nucleus after partial deafferentation. Exp Neurol 50:658-672.

Nicolelis MAL (1997) Dynamic and distributed somatosensory representations as the substrate for cortical and subcortical plasticity. Semin Neurosci 9:24-33.

Northgrave SA, Rasmusson DD (1996) The immediate effects of peripheral deafferentation on neurons of the cuneate nucleus in raccoons. Somatosen Mot Res 13:103-113.

Panetsos F, Nunez A, Avendano C (1995) Local anaesthesia induces immediate receptive field changes in nucleus gracilis and cortex. NeuroReport 7:150-152.

Panetsos F, Nunez A, Avendano C (1997) Electrophysiological effects of temporary deafferentation on two characterized cell types in the nucleus gracilis of the rat. Eur J Neurosci 9:563-572.

Pettit MJ, Schwark HD (1993) Receptive field reorganization in dorsal column nuclei during temporary denervation. Science 262:2054-2056.

Pettit MJ, Schwark HD (1996) Capsaicin-induced rapid receptive field reorganization in cuneate neurons. J Neurophysiol 75:1117-1125.

Rasmusson DD (1988) Projections of digit afferents to the cuneate nucleus in the raccoon before and after partial deafferentation. J Comp Neurol 277:549-556.

Rasmusson DD, Louw DF, Northgrave SA (1993) The immediate effects of peripheral denervation on inhibitory mechanisms in the somatosensory thalamus. Somatosen Mot Res 10:69-80.

Silva AC, Rasey SK, Wu X, Wall JT (1996) Initial cortical reactions to injury of the median and radial nerves to the hands of adult primates. J Comp Neurol 366:700-716.

Stojic AS, Lane RD, Killackey HP, Qadri BA, Rhoades RW (1998) Thalamocortical and intracortical projections to the forelimb-stump SI representation of rats that sustained neonatal forelimb removal. J Comp Neurol 401:187-204.

Sur M, Nelson RJ, Kaas JH (1982) Representations of the body surface 
in cortical areas $3 \mathrm{~b}$ and 1 of squirrel monkeys: comparisons with other primates. J Comp Neurol 211:177-192.

Turnbull BG, Rasmusson DD (1990) Acute effects of total or partial digit denervation on raccoon somatosensory cortex. Somatosen Mot Res 7:365-389.

Waite PME (1984) Rearrangement of neuronal responses in the trigeminal system of the rat following peripheral nerve section. J Physiol (Lond) 352:425-445.

Wall JT, Nepomuceno V, Rasey SK (1993) Nerve innervation of the hand and associated nerve dominance aggregates in the somatosensory cortex of a primate (squirrel monkey). J Comp Neurol 337:191-207.

$\mathrm{Xu} \mathrm{J,} \mathrm{Wall} \mathrm{JT} \mathrm{(1996)} \mathrm{Cutaneous} \mathrm{representations} \mathrm{of} \mathrm{the} \mathrm{hand} \mathrm{and} \mathrm{other}$ body parts in the cuneate nucleus of a primate, and some relationships to previously described cortical representations. Somatosen Mot Res 13:187-197.

Xu J, Wall JT (1997a) Rapid changes in brainstem maps of adult primates after peripheral injury. Brain Res 774:211-215.

Xu J, Wall JT (1997b) Rapid functional reorganization in primate cuneate nucleus and its potential anatomical substrates. Soc Neurosci Abstr 23:437.

Xu J, Wall JT (1999) Normal functional organization of tactile inputs from the hand in the cuneate nucleus and its representation in cortical area 3b. J Comp Neurol, in press.

Zhang SP, Rowe MJ (1997) Quantitative analysis of cuneate neurone responsiveness in the cat in association with reversible, partial deafferentation. J Physiol (Lond) 505:769-783. 